\title{
On a New Cannabinoid Classification System: A Sight on the Illegal Market of Novel Psychoactive Substances
}

\author{
Vadim Shevyrin, ${ }^{1}$ Vladimir Melkozerov, ${ }^{2}$ Gregory W. Endres, ${ }^{3}$ Yuri Shafran, ${ }^{1, *}$ and Yuri Morzherin ${ }^{1}$
}

\begin{abstract}
Synthetic cannabinoids are one of the most rapidly expanding classes of novel psychoactive substances found in illegal markets. These substances have evolved to the point that many examples no longer fit with the traditional cannabinoid classification system, where assignment of these compounds is difficult and ambiguous, leading to inconsistencies in regard to their chemical structures. This and other drawbacks can result in misunderstandings between forensic scientists and legal disciplines, complicating efforts toward improving the inadequacies of current antidrug laws. After a critical review, we offer an updated yet simplified cannabinoid classification system with the intention to facilitate interdisciplinary communication.
\end{abstract}

Keywords: drug abuse; synthetic cannabinoids; classification; new psychoactive substances

Traditional "cannabinoids" or "phytocannabinoids" include at least 66 biologically active terpene phenolic compounds, derivatives of two-substituted 5-amylresorcine, that are found in Cannabis sativa herb ${ }^{1,2}$ or are the products thereof such as herbal cannabis ("marihuana"), cannabis resin ("hashish"), and liquid cannabis ("cannabis oil"). ${ }^{3}$ Their synthetic analogues capable of binding to cannabinoid receptors ${ }^{4,5}$ are also generally referred to as "cannabinoids." The understanding of "cannabinoids" and their complex biological activities is tightly connected with the search for new pharmacological medicines, driven by their structure-activity relationship with the cannabinoid receptors. From this point of view, the meaning of the term "cannabinoid" relates to the effect on or the affinity to the cannabinoid receptors. Such compounds could be divided into cannabimimetics possessing cannabinoid activity (agonists) and antagonists capable of binding to cannabinoid receptors without causing cannabinoid effects but blocking the receptors for other compounds. ${ }^{4-6}$
From the chemical point of view, "cannabinoids" embrace a variety of diverse structures that served a basis for a classification system that has become the current standard in the beginning of the 21 st century. According to this classification system, cannabinoids are divided into the following classes. ${ }^{5-7}$

1. Classical cannabinoids: derivatives of dibenzopyran (Fig. 1), namely $\Delta^{9}$-tetrahydrocannabinol (THC), its isomers, and its structurally related synthetic analogues, for example, HU-210, prepared in $1988 .^{8}$

2. Nonclassical cannabinoids: synthetic derivatives of cyclohexylphenol (or 3-arylcyclohexanole), for example, CP 47,497 and CP 55,940 (Fig. 1), synthesized by US Pfizer company. ${ }^{9-11}$

3. Hybrid cannabinoids: to this class, some compounds that were modeled to combine structural features of both classical and nonclassical cannabinoids could be conventionally referred. A series

\footnotetext{
${ }^{1}$ Institute of Chemistry and Technology, Ural Federal University, Ekaterinburg, Russian Federation.

${ }^{2}$ Expert and Criminalistic Center, Main Agency of the Ministry of the Interior of the Russian Federation, Sverdlovsk Region Branch, Ekaterinburg, Russian Federation.

${ }^{3}$ Cayman Chemical Company, Ann Arbor, Michigan.

*Address correspondence to: Yuri Shafran, PhD, Institute of Chemistry and Technology, Ural Federal University, 19 Mira Street, 620002 Ekaterinburg, Russian Federation, E-mail: yu.m.shafran@urfu.ru
}

(C) Vadim Shevyrin et al. 2016; Published by Mary Ann Liebert, Inc. This Open Access article is distributed under the terms of the Creative Commons License (http://creativecommons.org/licenses/by/4.0), which permits unrestricted use, distribution, and reproduction in any medium, provided the original work is properly credited. 

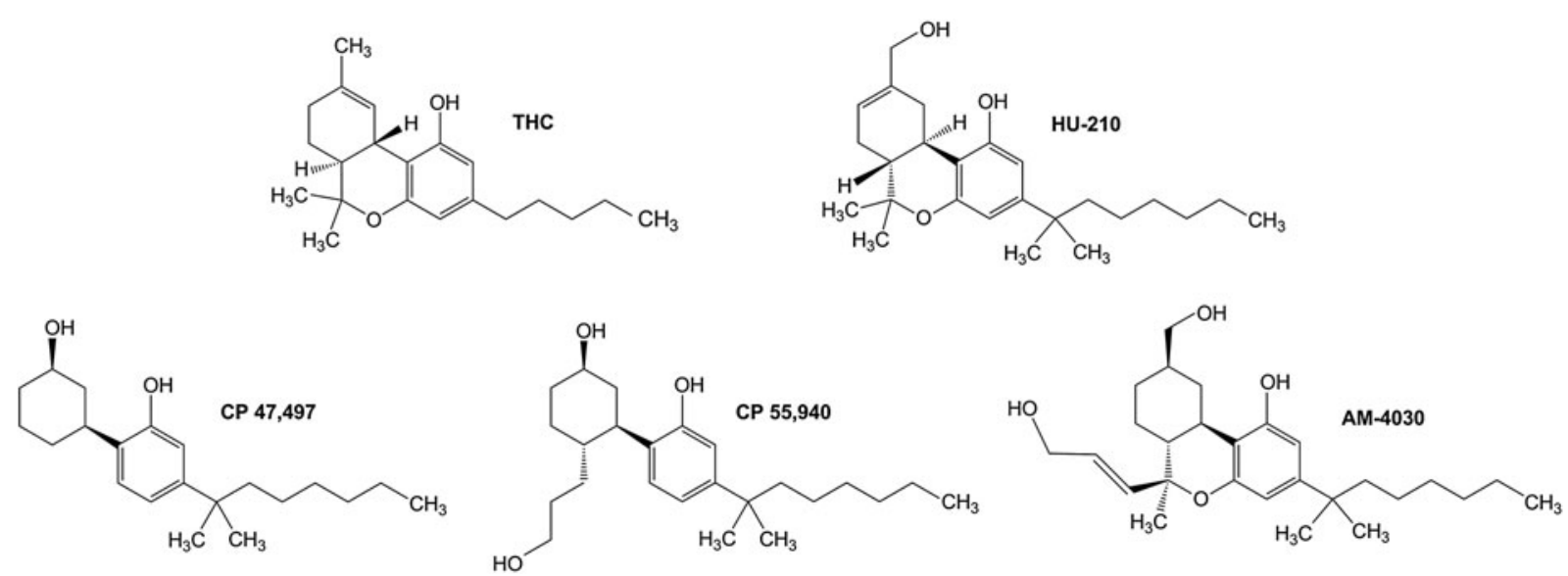

FIG. 1. Chemical structures of some classical, nonclassical, and hybrid cannabinoids.

of such compounds was prepared by the authors of the articles. ${ }^{12-14}$ An example could be found as AM- $4030^{15}$ in Figure 1.

4. Aminoalkylindoles: large class of compounds that take origin from a series prepared in $1991,{ }^{16}$ which gave the name to the whole class, including pharmacologically interesting WIN55,212-2 (Fig. 2). Further development of this class of synthetic cannabinoids was conducted by J.W. Huffman and A. Makriyannis laboratories, which prepared and studied pharmacological activity of a large number of 3-naphthoylindoles, ${ }^{17-22} 3$-phenylacetylindoles, ${ }^{23}$ 3-benzoylindoles, ${ }^{24,25}$ and naphthylmethylindoles. ${ }^{26}$ The aminoalkylindole chemical class was subdivided into the following groups: naphthoylindoles (A), phenylacetylindoles (B), benzoylindoles (C), and naphthylmethylindoles (D) (Fig. 2). Unfortunately, the first three groups were among the most prevalent chemical structures found in "herbal" smoking mixtures that were first detected in 2004 and are still prevalent today. ${ }^{4-6,27-32}$

5. Eicosanoids: endocannabinoids and their synthetic analogues. The primary endocannabinoids are the arachidonic acid derivatives

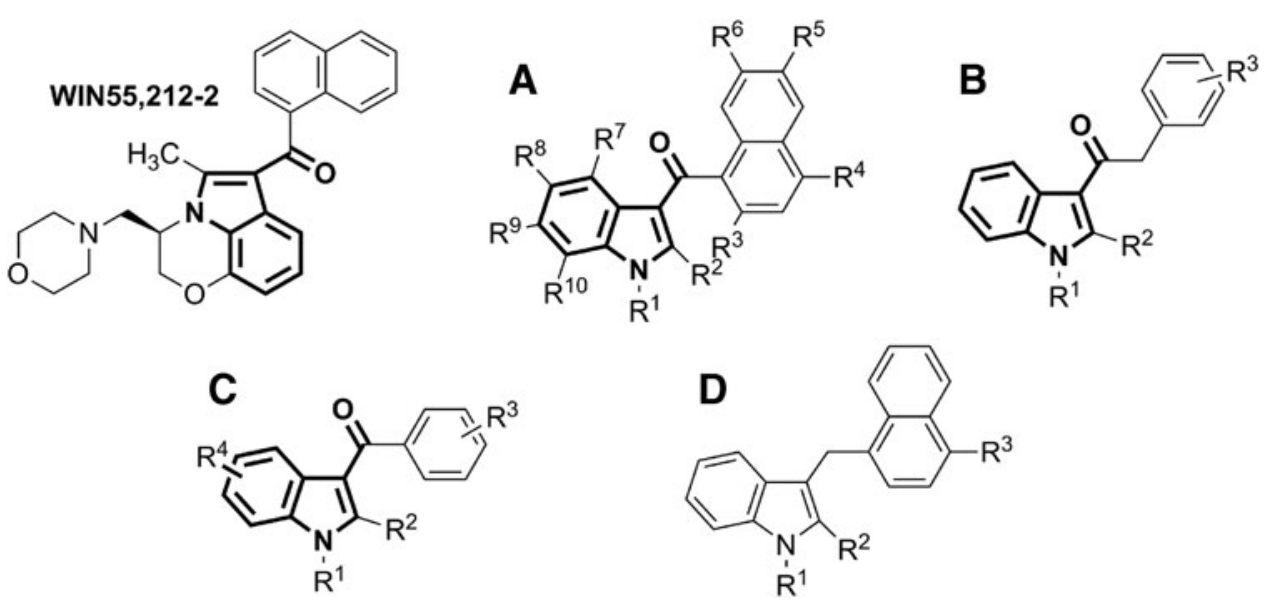

FIG. 2. Chemical structure of aminoalkylindoles: naphthoylindoles (A), phenylacetylindoles (B), benzoylindoles (C), and naphthylmethylindoles (D) (basic structural fragment of most compounds of the class is highlighted in bold). 

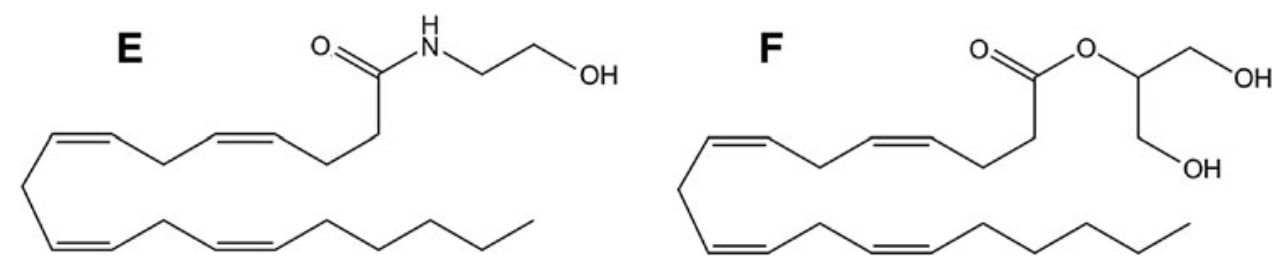

FIG. 3. N-Arachidonoylethanolamine (anandamide) (E) and 2-arachidonoylglycerol (F).

$\mathrm{N}$-arachidonoylethanolamine (anandamide; AEA) or 2-arachidonoylglycerol (2-AG) (Fig. 3), discovered in 1992-1995. ${ }^{33-35}$

6. Other cannabinoids: heterocyclic compounds that are not attributed to a specific class based on small number of compounds prepared or insufficient understanding of activity. This class could be exemplified by known groups such as diarylpyrazoles (e.g., SR141716A and SR144528) (6,37 $^{36}$ and 3-naphthoylpyrroles ${ }^{38,39}$ (Fig. 4).

This classification system was later expanded to include adamantoylindoles, cyclopropoylindoles, and indolecarboxamides within the category of aminoalkylindoles. ${ }^{40}$ However, indazolecarboxamides, another emerging group of synthetic cannabinoids in illegal markets, were added to the category of "others" since they technically do not fit within the general aminoalkylindole category despite differing from their indole counterpart by only a single nitrogen atom.

One of the first representatives of the "adamantylindole" group with the general formula J (Fig. 5), tested for cannabinoid activity, was (adamantan-1-yl)-1-[(1methylpiperidin-2-ylmethyl)-1 $H$-indol-3-yl]methanone (AM-1248), prepared in A. Makriyannis laboratory. ${ }^{21}$ Emergence of the $N$-pentyl analogue of AM-1248 in the market of novel psychoactive substances (NPSs) $^{41,42}$ in 2010 prompted a sudden need for assessment and cannabinoid classification since no data on the synthesis or on cannabimimetic activity of the compound were described in publicly available literature to date. Biological activity of (adamantan-1-yl)(1-pentyl$1 \mathrm{H}$-indol-3-yl)methanone was published 2 years after it appeared in the illegal market of NPSs ${ }^{43}$ and required addition as a subcategory to the former classification system. $^{44}$

Derivatives of 3-(2,2,3,3-tetramethylcyclopropanecarbonyl)indole with general formula K (Fig. 5) that were synthesized in Abbott Laboratories ${ }^{4-48}$ were combined into "cyclopropoylindoles" group. Representatives of this group have first appeared as designer drugs in Russia in summer of $2011 .^{49}$

Syntheses and pharmacological properties of cannabinoids from indolecarboxamides (or indole-3carboxamides) group (structure $\mathbf{L}$ in Fig. 5) are reported ${ }^{43,50,51}$; however, occurrence of most new compounds of this group is due to the market of designer drugs. The first representative of the group in the illegal market of NPSs, $\mathrm{N}$-adamantylamide of 1-pentylindole-3-carboxylic acid (structure $\mathrm{L}, \mathrm{R}=$ pentyl, $\mathrm{R}^{1}=1$-adamantyl in Fig. 5), was detected in Japan in the end of $2011 .{ }^{52}$ Beginning from this
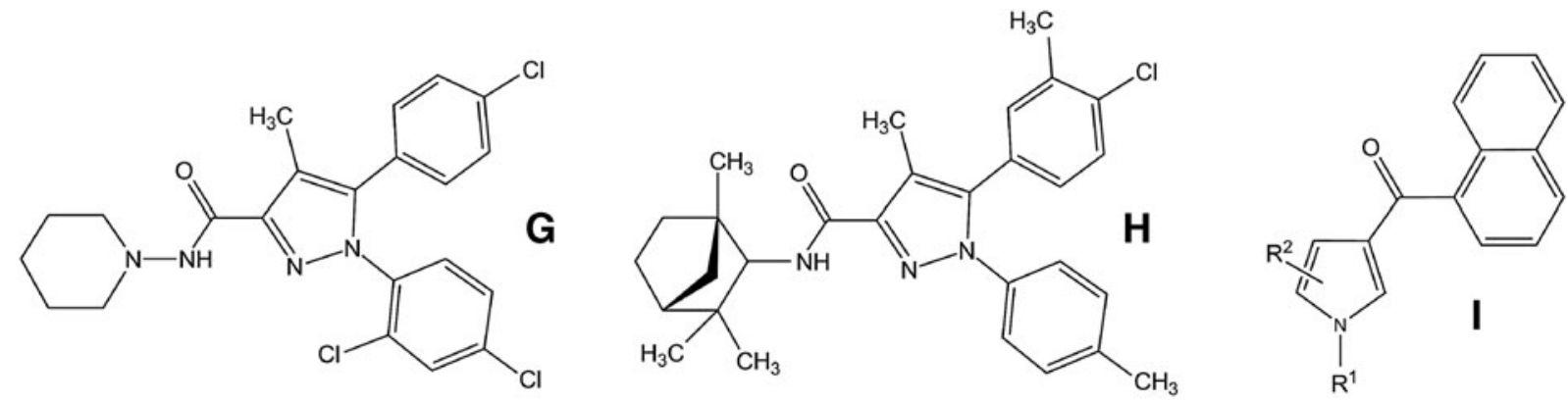

FIG. 4. Structures of SR141716A (G), SR144528 (H), and 3-naphthoylpyrroles (I). 

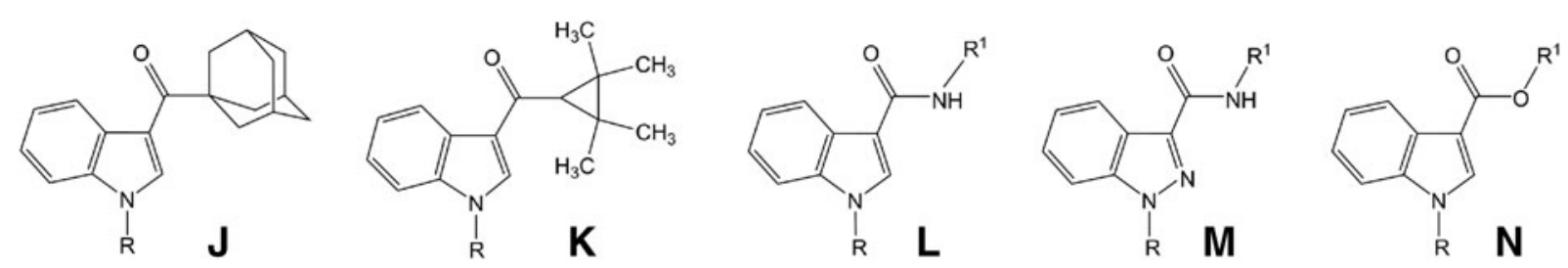

FIG. 5. Structures of adamantanecarbonylindoles (J), cyclopropanecarbonylindoles (K), indole-3carboxamides (L), indazole-3-carboxamides (M), and indole-3-carboxylates (N).

date, this group of cannabinoids grows constantly, its structural diversity being determined by availability of amines used for the synthesis. Representatives of the group (structure $\mathbf{L}, \mathrm{R}^{1}=1$-naphthyl, ${ }^{53-56}$ 1 -carbamoylalkyl, ${ }^{57,58}$ and 1-methoxycarbonylalkyl ${ }^{59}$ shown in Fig. 5) were identified in the products sold in the illegal market of NPSs at present. To the same group, amide derived from cyclic amine like (4methylpiperazin-1-yl)(1-pentyl-1H-indol-3-yl)methanone ("MEPIRAPIM") ${ }^{60}$ should be referred.

Modification of aminoalkylindoles consisting of insertion of additional nitrogen atom in the indole ring and replacing the ketone with a carboxamide functional group leads to a new group of synthetic cannabinoids, indazolecarboxamides (to be exact, indazole-3-carboxamides, structure $\mathbf{M}$ in Fig. 5). A great number of such compounds were prepared and tested in Prof. A. Makriyannis Laboratory ${ }^{61}$ and by Pfizer, Inc. ${ }^{62,63}$ The results published in these articles were applied to the synthesis of designer drugs that appeared in the illegal NPSs market simultaneously with compounds from indole-3-carboxamides group bearing analogous substituents. ${ }^{52,54,57,58,64-74}$ The divergence of these similar structures into separate classifications, the overly specific "aminoalkylindoles" group and "other," highlights the need for an alternative classification system that is amenable to an ever expanding repertoire of cannabinoids.

With the onset of the "spice" cannabinoids in the illegal market of NPSs observed since 2011 and rapid expansion of the chemical adulterants in such products, the traditional classification system has become insufficient as a means to categorize the structural diversity driven by the illegal market of NPSs. ${ }^{44,75}$ These substances are often referred to as designer drugs based on nefarious attempts to circumvent regulations where an NPS is "designed" around existing legislation. The "aminoalkylindole" structural class continues to evolve in response to specific regulatory listings and the listing of specific examples has proven to be insufficient due to a rapid NPS life-cycle that is a far more efficient process than adapting new legislation. Hundreds of cannabinoid NPSs have been detected over the past decade and the currently used classification system limits the vast majority of these substances to the category of "aminoalkylindole" or "other." Furthermore, the subject of synthetic cannabinoids is no longer unique to scientific discussion but is now a topic of concern from a legal and public health perspective. For this reason, it is of particular importance that a clear distinction is made between phytocannabinoids and synthetic cannabinoids based on relative health risks resulting from abuse and from their disparate regulations. In contrast to the current classification system with seven categories based on structure alone, we propose three general categories based on natural occurrence with subcategories based on structure. According to this newly proposed classification system, cannabinoids are divided into the following classes.

Phytocannabinoids: Naturally occurring chemical compounds that are derived from Cannabis sativa, and related species of this plant are categorized as phytocannabinoids.

Endocannabinoids: Naturally occurring chemical compounds produced by living organisms that are associated with the cannabinoid receptors $(\mathrm{CB} 1$ and $\mathrm{CB} 2$ ) or more generally considered part of the endocannabinoid system.

Synthetic cannabinoids: Non-naturally occurring chemical compounds that either affect the endocannabinoid system or that are structural analogues of an endocannabinoid, phytocannabinoid, or other synthetic cannabinoids.

\section{Phytocannabinoids}
1.1. Tricyclic terpinoids
1.2. Bicyclic terpenoids
1.3. Other 

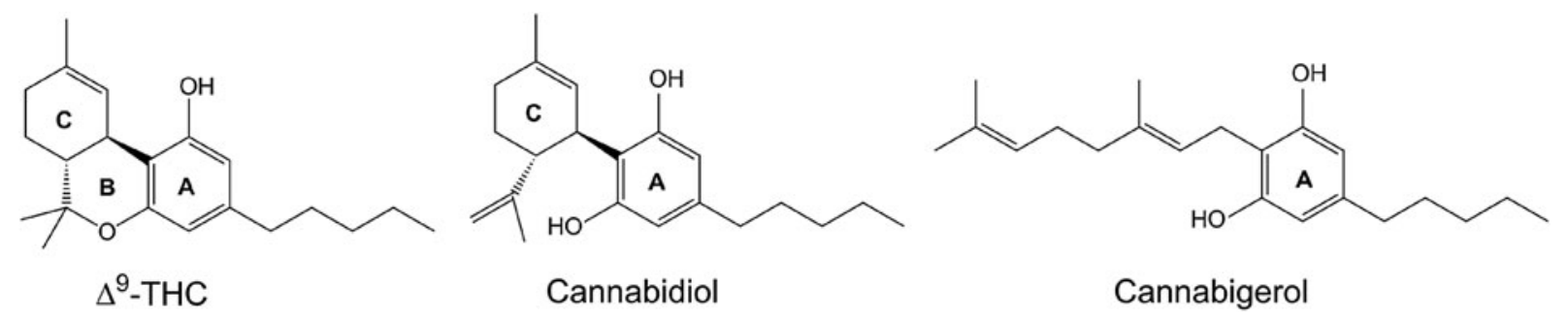

FIG. 6. Chemical structures of exemplary phytocannabinoids.

2. Endocannabinoids

2.1. AEA pathway

2.2. 2-AG pathway

2.3. Other eicosanoids

3. Synthetic cannabinoids

3.1. Phytocannabinoid-similar

3.1.1. Tricyclics

3.1.2. Bicyclics

3.1.3. Other

3.2. Endocannabinoid-related

3.2.1. Eicosanoid-similar

3.2.2. Endocannabinoid modulators

3.3. Indole-similar

\subsubsection{Indoles}

3.3.1.1. 3-Carbonylindoles

3.3.1.1.1. Naphthoylindoles

3.3.1.1.2. Phenylacetylindoles

3.3.1.1.3. Benzoylindoles

3.3.1.1.4. Cycloalkanecarbonylindoles

3.3.1.1.4.1. Adamantanecarbonylindoles

3.3.1.1.4.2. Cyclopropanecarbonylindoles

3.3.1.1.5. Indole-3-carboxamides

3.3.1.1.6. Indole-3-carboxylates

3.3.1.1.7. Others 3-carbonylindoles

\subsubsection{Indazoles}

3.3.2.1. 3-Carbonylindazoles

3.3.2.1.1. Naphthoylindazoles

3.3.2.1.2. Indazole-3-carboxamides

3.3.2.1.3. Indazole-3-carboxylates

\subsubsection{Benzimidazoles}

3.3.4.1. 2-Carbonylbenzimidazoles

3.3.4.1.1. 2-Naphthoylbenzimidazoles

\subsubsection{Other azaindoles}

\subsection{Indenes}

3.4.1. Naphthylmethylindenes

\subsection{Pyrrole-similar}

\subsubsection{Pyrroles}

3.5.1.1. 3-Naphthoylpyrroles

\subsubsection{Pyrrazoles}

3.5.2.1. Diarylpyrazoles

\subsection{Carbazole-similar}

3.7. Miscellaneous

The former "classical" cannabinoid designation includes both the natural $\Delta^{9}$-THC and synthetically derived HU-210 based on their characteristic ABCtricyclic terpenoid ring structure. Whereas in the new system, HU-210, an early example of a spice adulterant is categorized as a synthetic cannabinoid. Likewise, the AC-bicyclic compounds cannabidiol and synthetically derived CP-55,940 would be categorized as

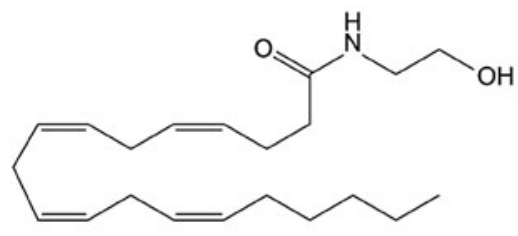

AEA

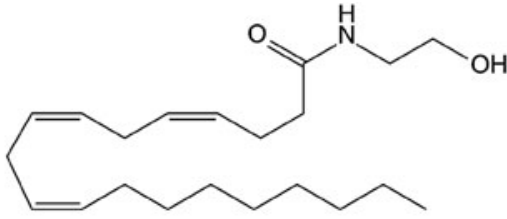

5,8,11-eicosatrienoyl (mead) ethanolamide

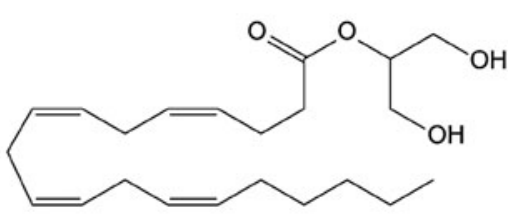

2-AG

FIG. 7. Chemical structures of exemplary endocannabinoids. 


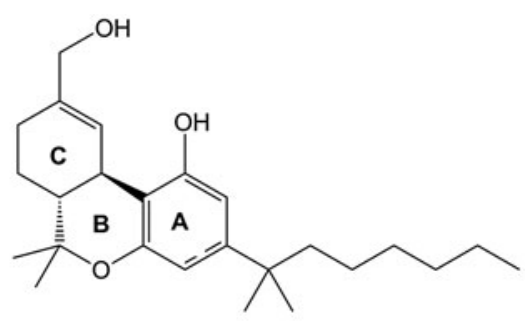

HU-210

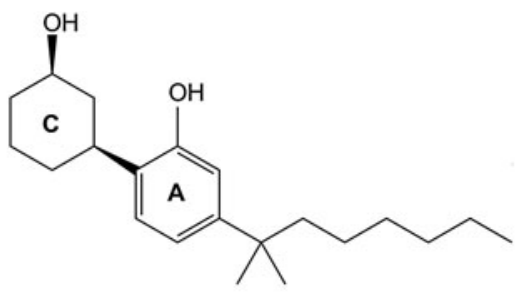

CP- $-47,497$<smiles>CCCCCc1cc(O)cc(OCCCCCCCCCCCC(=O)NC2CC2)c1</smiles><smiles>NC(=O)c1cccc(-c2cccc(OC(=O)NC3CCCCC3)c2)c1</smiles>

URB-597

FIG. 8. Chemical structures of exemplary phytocannabinoid-similar and endocannabinoid-related synthetic cannabinoids.

"nonclassical" in the former system, whereas in the new system based on occurrence, plant-based $\Delta^{9}$-THC and cannabidiol are classified as phytocannabinoids and subcategorized based on structure. Isotopically labeled forms, although synthetically derived, are also categorized as phytocannabinoids. Primary examples of the ABC-tricyclic, AC-bicyclic, and "other" terpenoid subcategories of the phytocannabinoid class include $\Delta^{9}$ THC, cannabidiol, and cannabigerol (Fig. 6).

Within the endocannabinoid category, the new classification system also designates inclusion based on natural occurrence such as the primary natural ligands, arachidonyl ethanolamide (anandamide, AEA) and 2arachidonyl glycerol (2-AG). Biosynthetic precursors and other eicosanoids such as 5,8,11-eicosatrienoyl (mead) ethanolamide, ${ }^{76} \mathrm{~N}$-dihomo- $\gamma$-linolenoyl ethanolamine, $^{77}$ and $N$-docosatetraenoyl ethanolamine ${ }^{77}$ that bind to the cannabinoid receptors also fall within this category (Fig. 7). However, endocannabinoid modulators such as URB-597, an inhibitor of the fatty acid amide hydrolase enzyme that is responsible for the degradation of AEA, are categorized as synthetic cannabinoids.

Synthetic cannabinoids that are structurally related to a phytocannabinoid-similar counterpart are designated to Section 3.1.1-3.1.3 corresponding to their terpenoid structure using the same $A B C$ ring system designations (Fig. 8). For example, the synthetic cannabinoids HU-210 ${ }^{78}$ and CP-47,497, ${ }^{79}$ both detected as

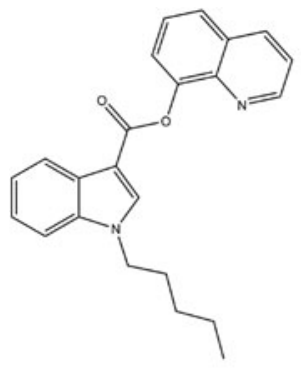

PB-22 (indole)

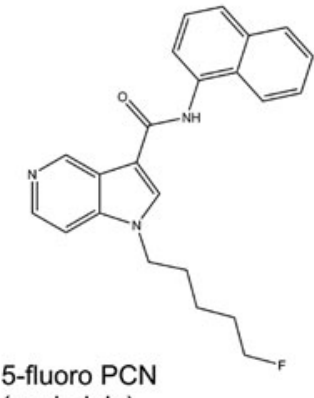
(azaindole)
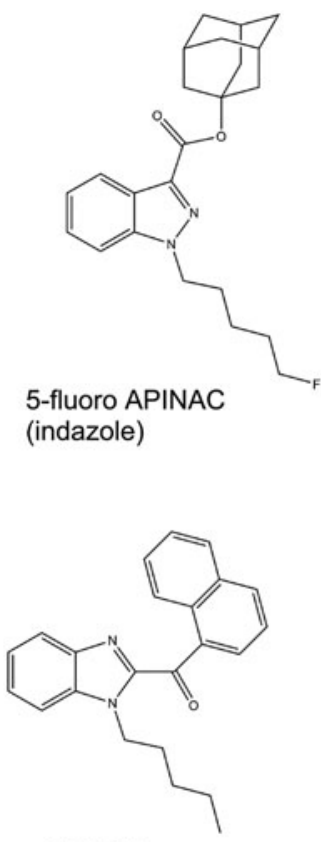

BIM-018 (benzimidazole)

FIG. 9. Chemical structures of exemplary indole-similar synthetic cannabinoid subcategories.

adulterants in herbal smoking mixtures, in this system, 


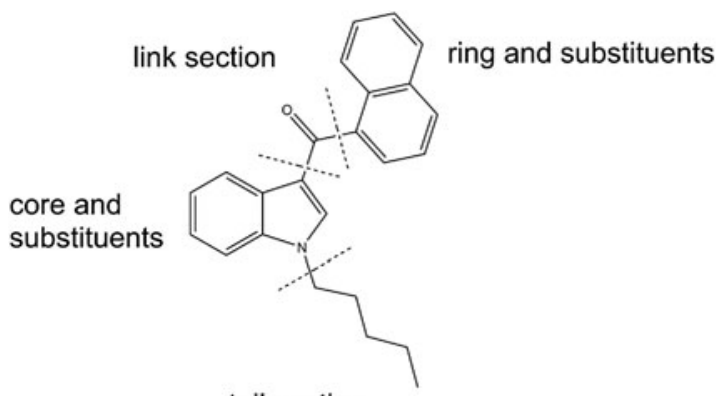

tail section

EMCDDA pharmacophore model

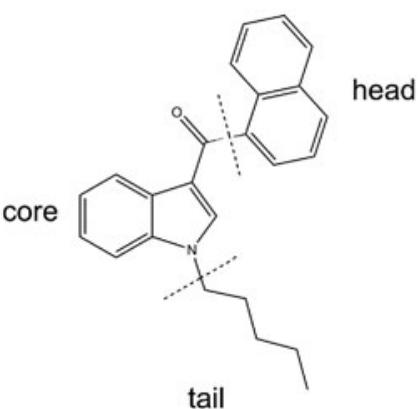

Cayman 'Flipbook' pharmacophore model

FIG. 10. Pharmacophore-based models of synthetic cannabinoids.

are categorized using the same structural criteria as the phytocannabinoids but segregated from their natural counterparts.

A simplified approach to the general "aminoalkylindole" category of synthetic cannabinoids is to replace this terminology with language that is based on the central pharmacophore with multiple, specific subtypes. Pharmacophore models of synthetic cannabinoids have been described ${ }^{80,81}$ and this concept and terminology have been utilized for the purpose of assessment of structural similarity. ${ }^{81}$ It is the opinion of the authors that a "core" subunit of a three-component pharmacophore model will most effectively provide logical subcategories for the synthetic cannabinoids. With this approach, the "indole-similar" core may be further divided into pharmacophore-based groups that are similar aromatic systems differing only by the presence of an additional nitrogen heteroatom including indazoles, benzimidazoles, ${ }^{82}$ and other azaindoles (Fig. 9). It should be noted that the examples provided in Figure 9 would be categorized in the category of "other," based on the former classification system that is dependent on an overly specific "core" + "head group" pharmacophore requirement (i.e., naphthoylindoles) described in Figure 10. The latter classification requirement is dependent only on the core structure that cast a wider net on the diverse functionality observed with synthetic cannabinoid designer drugs. The "core" pharmacophore is the logical choice to provide such a basis as more chemical diversity is observed within the "head" and "tail" pharmacophores. Although no exemplary compounds for Sections 3.43.6 covering indenes, pyrroles, pyrrazoles, and carbazoles are provided in this discussion, the same logic and rationale for a pharmacophore-based categorization system may be applied.

It is quite understandable that in the view of constant development of the chemistry of new synthetic cannabinoids that any new suggested classification system will inevitably require updating, including the determination of new and separate groups and classes. Nevertheless we believe that our suggested classification adequately captures the structural diversity of synthetic cannabinoids, thus improving their systematization. As a result, this updated classification system could serve practical basis for improvement of national and international legislations to put analogues of known synthetic cannabinoids under control with the aim to prevent their propagation as designer drugs.

\section{Author Disclosure Statement}

No competing financial interests exist.

\section{References}

1. Pertwee RG. Pharmacological and therapeutic targets for $\Delta 9$ tetrahydrocannabinol and cannabidiol. Euphytica. 2004;140:73-82.

2. Elsohly MA, Desmond S. Chemical constituents of marijuana: the complex mixture of natural cannabinoids. Life Sci. 2005;78:539-548.

3. United Nation Office on Drugs and Crime (UNODC) Recommended methods for the identification and analysis of cannabis and cannabis products, 2009. www.unodc.org/documents/scientific/ST-NAR-40Ebook.pdf Accessed December 1, 2015.

4. Castaneto MS, Gorelick DA, Desrosiers NA, et al. Synthetic cannabinoids: epidemiology, pharmacodynamics, and clinical implications. Drug Alcohol Depend. 2014;144:12-41.

5. United Nation Office on Drugs and Crime (UNODC). Synthetic cannabinoids in herbal products, 2011. www.unodc.org/documents/scientific/ Synthetic_Cannabinoids.pdf Accessed December 1, 2015.

6. Auwärter V, Kneisel S, Hutter, et al. Synthetische Cannabinoide. Forensische Relevanz und Interpretation analytischer Befunde. Rechtsmedizin. 2012;22:259-271.

7. Howlett AC, Barth F, Bonner TI, et al. International Union of Pharmacology. XXVII. Classification of cannabinoid receptors. Pharmacol Rev. 2002;54:161-202. 
8. Mechoulam R, Feigenbaum JJ, Lander N, et al. Enantiomeric cannabinoids: stereospecificity of psychotropic activity. Experientia. 1988;44:762-764.

9. Harbert CA, Johnson MR, Melvin LS-J. 3-[Hydroxy-4-(substituierte)phenyl]-cycloalkanon- und -cycloalkanolderivate, Verfahrenzuihrer Herstellung und diese enthaltende Arzneimittel. German Patent, DE 2839836, 1979.

10. Weissman A, Milne GM, Melvin LS-J. Cannabimimetic activity from CP47,497, a derivative of 3-phenylcyclohexanol. J Pharmacol Exp Ther. 1982;223:516-523.

11. Johnson MR, Melvin LS. 2-Hydroxy-4-(substituted) phenyl cycloalkanes and derivatives. US Patent, US 4371720, 1983.

12. Tius MA, Hill WAG, Zoul XL, et al. Classical/non-classical cannabinoid hybrids; stereochemical requirements for the southern hydroxyalkyl chain. Life Sci. 1995;56:2007-2012.

13. Drake DJ, Jensen RS, Busch-Petersen J, et al. Classical/nonclassical hybrid cannabinoids: southern aliphatic chain-functionalized C-6 $\beta$-methyl ethyl, and propyl analogues. J Med Chem. 1998;41:3596-3608.

14. Harrington $P E$, Stergiades $I A$, Erickson J, et al. Synthesis of functionalized cannabinoids. J Org Chem. 2000;65:6576-6582.

15. Razdan RK. Structure-activity relationships of classical cannabinoids. The cannabinoid receptors. Humana Press: New York, 2009;3-19.

16. Bell MR, D'Ambra TE, Kumar V, et al. Antinociceptive (aminoalkyl)indoles. J Med Chem. 1991;34:1099-1110.

17. Huffman JW, Dai D, Martin BR, et al. Design, synthesis and pharmacology of cannabimimetic indoles. Bioorg Med Chem Lett. 1994;4:563-566.

18. Huffman JW, Zengin G, Wu M-J, et al. Structure-activity relationships for 1-alkyl-3-(1-naphthoyl)indoles at the cannabinoid CB1 and CB2 receptors: steric and electronic effects of naphthoyl substituents. New highly selective CB2 receptor agonists. Bioorg Med Chem. 2005;13:89-112.

19. Martin BR, Huffman JW. $C_{2}$-selective cannabinoid analogues. US Patent, US 0009903, 2005.

20. D'Ambra TE, Eissenstat MA, Abt J, et al. C-attached aminoalkylindoles: potent cannabinoid mimetics. Bioorg Med Chem Lett. 1996;6:17-22.

21. Makriyannis A, Deng H. Cannabimimetic indole derivatives. US Patent, US $0119234,2005$.

22. Makriyannis A, Deng $H$. Receptor selective cannabimimetic aminoalkylindoles. US Patent, US 7820144, 2010.

23. Huffman JW, Szklennik PV, Almond A, et al. 1-Pentyl-3-phenylacetylindoles, a new class of cannabimimetic indoles. Bioorg Med Chem Lett. 2005;15: 4110-4113.

24. Ross RA, Brockie HC, Stevenson LA, et al. Agonist-inverse agonist characterization at $\mathrm{CB}_{1}$ and $\mathrm{CB}_{2}$ cannabinoid receptors of $\mathrm{L} 759633, \mathrm{~L} 759656$ and AM630. Br J Pharmacol. 1999;126:665-672.

25. Deng $H$, Gifford AN, Zvonok A, et al. Potent cannabinergicindole analogues as radioiodinatablebrain imaging agents for the CB1 cannabinoid receptor. J Med Chem. 2005;48:6386-6392.

26. Huffman JW, Mabon R, Wu M-J, et al. 3-Indolyl-1-naphthylmethanes: new cannabimimeticindoles provide evidence for aromatic stacking interactions with the $\mathrm{CB}_{1}$ cannabinoid receptor. Bioorg Med Chem. 2003;11:539-549.

27. Auwärter V, Dresen S, Weinmann W, et al. 'Spice' and other herbal blends: harmless incense or cannabinoid designer drugs? J Mass Spectrom. 2009;44:832-837.

28. Uchiyama N, Kikura-Hanajiri R, Ogata J, et al. Chemical analysis of synthetic cannabinoids as designer drugs in herbal products. Forensic Sci Int. 2010;198:31-38.

29. Dresen S, Ferreiros N, Pütz M, et al. Monitoring of herbal mixtures potentially containing synthetic cannabinoids as psychoactive compounds. J Mass Spectrom. 2010;45:1186-1194.

30. Uchiyama N, Kawamura M, Kikura-Hanajiri R, et al. Identification and quantitation of two cannabimimetic phenylacetylindoles $\mathrm{JWH}-251$ and JWH-250, and four cannabimimetic naphthoylindoles JWH-081, JWH-015, JWH-200, and JWH-073 as designer drugs in illegal products. Forensic Toxicol. 2011;29:25-37.

31. Hudson S, Ramsey J. The emergence and analysis of synthetic cannabinoids. Drug Test Anal. 2011;3:466-478.

32. Kikura-Hanajiri R, Uchiyama N, Kawamura $M$, et al. Changes in the prevalence of new psychoactive substances before and after the introduction of the generic scheduling of synthetic cannabinoids in Japan. Drug Test Anal. 2014;6:832-839.

33. Mechoulam R, Ben-Shabat S, Hanus L, et al. Identification of an endogenous 2-monoglyceride, present in canine gut, that binds to the peripheral cannabinoid receptors. Biochem Pharmacol. 1995;50:83-90.
34. Sugiura T, Kodaka T, Kondo S, et al. 2-Arachidonoylglycerol, a putitative endogenous cannabinoid receptor ligand, induces rapid, transient elevation of intracellular free $\mathrm{Ca}^{2+}$ in neuroblastoma $\times$ glioma hybrid NG108-15 cells. Biochem Biophys Res Comm. 1996;229:58-64.

35. Pertwee RG. Cannabinoid pharmacology: the first 66 years. Br J Pharmacol. 2006;147:S163-S171.

36. Rinaldi-Carmona M, Barth F, Heaulme M, et al. SR141716A, a potent and selective antagonist of the brain cannabinoid receptor. FEBS Lett. 1994;350:240-244.

37. Rinaldi-Carmona M, Barth F, Millan J, et al. SR 144528, the first potent and selective antagonist of the $\mathrm{CB}_{2}$ cannabinoid receptor. J Pharmacol Exp Ther. 1998;284:644-650.

38. Lainton JAH, Huffman JW. I-Alkyl-3-(I-naphthoyl)pyrroles: a new class of cannabinoid. Tetrahedron Lett. 1995;36:1401-1404.

39. Tarzia G, Duranti A, Tontini A, et al. Synthesis and structure-activity relationships of a series of pyrrole cannabinoid receptor agonists. Bioorg Med Chem. 2003;11:3965-3973.

40. United Nation Office on Drugs and Crime (UNODC). Recommended methods for the identification and analysis of synthetic cannabinoid receptor agonists in seized materials, 2013. www.unodc.org/documents/scientific/ STNAR48_Synthetic_Cannabinoids_ENG.pdf Accessed December 1, 2015.

41. Jankovics $P$, Varadi $A$, Tolgyesi $L$, et al. Detection and identification of the new potential synthetic cannabinoids 1-pentyl-3-(2-iodobenzoyl)indole and 1-pentyl-3-(1-adamantoyl)indole in seized bulk powders in Hungary. Forensic Sci Int. 2012;214:27-32.

42. Kneisel $S$, Westphal $F$, Bisel $P$, et al. Identification and structural characterization of the synthetic cannabinoid 3-(1-adamantoyl)-1-pentylindole as an additive in 'herbal incense'. J Mass Spectrom. 2012;47:195-200.

43. Banister SD, Wilkinson SM, Longworth $M$, et al. The synthesis and pharmacological evaluation of adamantane-derived indoles: cannabimimetic drugs of abuse. ACS Chem Neurosci. 2013:4:1081-1092.

44. United Nation Office on Drugs and Crime (UNODC). World Drug Report 2013, 2013. www.unodc.org/unodc/secured/wdr/wdr2013/ World_Drug_Report_2013.pdf Accessed December 1, 2015.

45. Pace JM, Tietje K, Dart MJ, et al. 3-Cycloalcylcarbonyl indoles as cannabinoid receptor ligands. WIPO Patent, WO 069196 A1, 2006.

46. Frost JM, Dart MJ, Tietje KR, et al. Indol-3-ylcycloalkyl ketones: effects of $\mathrm{N} 1$ substituted indole side chain variations on $\mathrm{CB}_{2}$ cannabinoid receptor activity. J Med Chem. 2010;53:295-315.

47. Frost JM, Tietje K, Dart MJ, et al. Indoles are cannabinoid receptor ligands. US Patent, US 7750039 B2, 2010.

48. Frost JM, Tietje K, Dart MJ, et al. Novel indoles are cannabinoid receptor ligands. US Patent, US 0065685 A1, 2011.

49. Shevyrin V, Melkozerov V, Nevero A, et al. Identification and analytical properties of new synthetic cannabimimetics bearing 2,2,3,3tetramethylcyclopropanecarbonyl moiety. Forensic Sci Int. 2013;226:62-73.

50. Adam JM, Cairns J, Caulfield W, et al. Design, synthesis, and structureactivity relationships of indole-3-carboxamides as novel water soluble cannabinoid $\mathrm{CB}_{1}$ receptor agonists. Med Chem Commun. 2010;1:54-60.

51. Blaazer AR, Lange JHM, van der Neut MAW, et al. Novel indole and azaindole (pyrrolopyridine) cannabinoid (CB) receptor agonists: design, synthesis, structure-activity relationships, physicochemical properties and biological activity. Eur J Med Chem. 2011;46:5086-5098.

52. Uchiyama N, Kawamura M, Kikura-Hanajiri R, et al. Identification of two new-type synthetic cannabinoids, $\mathrm{N}$-(1-adamantyl)-1-pentyl-1H-indole-3carboxamide (APICA) and $\mathrm{N}$-(1-adamantyl)-1-pentyl- $1 \mathrm{H}$-indazole-3carboxamide (APINACA), and detection of five synthetic cannabinoids, AM-1220, AM-2233, AM-1241, CB-13 (CRA-13), and AM-1248, as designer drugs in illegal products. Forensic Toxicol. 2012;30:114-125.

53. Shevyrin V, Melkozerov V, Nevero A, et al. Analytical characterization of some synthetic cannabinoids, derivatives of indole-3-carboxylic acid. Forensic Sci Int. 2013;232:1-10.

54. Uchiyama N, Matsuda S, Kawamura M, et al. Characterization of four new designer drugs, 5-chloro-NNEl, NNEl indazole analog, $\alpha$-PHPP and $\alpha$-POP with 11 newly distributed designer drugs in illegal products. Forensic Sc Int. 2014:243:1-13.

55. Sasaki C, Saito T, Shinozuka T, et al. A case of death caused by abuse of a synthetic cannabinoid N-1-naphthalenyl-1-pentyl-1H-indole-3carboxamide. Forensic Toxicol. 2015;33:165-169.

56. Uchiyama N, Shimokawa Y, Kikura-Hanajiri R, et al. A synthetic cannabinoid FDU-NNEl, two $2 \mathrm{H}$-indazole isomers of synthetic cannabinoids AB-CHMINACA and NNEI indazole analog (MN-18), a phenethylamine 
derivative $\mathrm{N}-\mathrm{OH}-\mathrm{EDMA}$, and a cathinone derivative dimethoxy- $\alpha-\mathrm{PHP}$ newly identified in illegal products. Forensic Toxicol. 2015;33:244-259.

57. Uchiyama N, Matsuda S, Kawamura M, et al. Two new-type cannabimimetic quinolinyl carboxylates, QUPIC and QUCHIC, two new cannabimimetic carboxamide derivatives, ADB-FUBINACA and ADBICA, and five synthetic cannabinoids detected with a thiophene derivative $\alpha$-PVT and an opioid receptor agonist $\mathrm{AH}-7921$ identified in illegal products. Forensic Toxicol. 2013;31:223-240.

58. Banister SD, Moir M, Stuart J, et al. Pharmacology of indole and indazole synthetic cannabinoid designer drugs AB-FUBINACA, ADB-FUBINACA, ABPINACA, ADBPINACA, 5F-AB-PINACA, 5F-ADB-PINACA, ADBICA, and 5FADBICA. ACS Chem Neurosci. 2015;6:1546-1559.

59. Shevyrin V, Morzherin Y, Melkozerov V, et al. New synthetic cannabinoidmethyl 2-\{[1-(5-fluoropentyl)-3-methyl-1H-indol-3-ylcarbonyl]amino butyrate-as a designer drug. Chem Heterocycl Compd. 2014;50: 583-586.

60. Uchiyama N, Shimokawa Y, Matsuda S, et al. Two new synthetic cannabinoids, AM-2201 benzimidazole analog (FUBIMINA) and (4methylpiperazin-1-yl)(1-pentyl-1H-indol-3-yl)methanone (MEPIRAPIM), and three phenethylamine derivatives, 25H-NBOMe 3,4,5-trimethoxybenzyl analog, 25B-NBOMe, and 2C-N-NBOMe, identified in illegal products. Forensic Toxicol. 2014;32:105-115.

61. Makriyannis A, Liu Q. Heteroindanes: a new class of potent cannabimimetic ligands. WIPO Patent, WO 03035005, 2003.

62. Buchler IP, Hayes MJ, Hedge SG, et al. Indazole derivatives. WIPO Patent, WO 106982, 2009.

63. Buchler IP, Hayes MJ, Hedge SG, et al. Indazole derivatives. WIPO Patent WO 106980, 2009

64. Uchiyama N, Matsuda S, Wakana D, et al. New cannabimimetic indazole derivatives, $\mathrm{N}$-(1-amino-3-methyl-1-oxobutan-2-yl)-1-pentyl- $\mathrm{H}$-indazole3-carboxamide (AB-PINACA) and $\mathrm{N}$-(1-amino-3-methyl-1-oxobutan-2-yl)1-(4-fluorobenzyl)-1H-indazole-3-carboxamide (AB-FUBINACA), identified as designer drugs. Forensic Toxicol. 2013;31:93-100.

65. Uchiyama N, Shimokawa Y, Kawamura M, et al. Chemical analysis of a benzofuran derivative, 2-(2-ethylaminopropyl)benzofuran (2-EAPB), eight synthetic cannabinoids, five cathinone derivatives, and five other designer drugs newly detected in illegal products. Forensic Toxicol. 2014;32:266-281.

66. Wurita A, Hasegawa K, Minakata K, et al. A large amount of new designer drug diphenidine coexisting with a synthetic cannabinoid 5-fluoro-ABPINACA found in a dubious herbal product. Forensic Toxicol. 2014;32:331-337.

67. Shevyrin V, Melkozerov V, Nevero A, et al. Synthetic cannabinoids as designer drugs: new representatives of indol-3-carboxylates series and indazole-3-carboxylates as novel group of cannabinoids. Identification and analytical data. Forensic Sci Int. 2014;244:263-275.

68. Shevyrin V, Melkozerov V, Nevero A, et al. 3-Naphthoylindazoles and 2naphthoylbenzoimidazoles as novel chemical groups of synthetic cannabinoids: chemical structure elucidation, analytical characteristics and identification of the first representatives in smoke mixtures. Forensic Sci Int. 2014;242:72-80.

69. Shevyrin V, Melkozerov V, Nevero A, et al. Synthetic cannabinoids of indazole-3-carboxamide group bearing N-1-methoxycarbonylalkyl moiety as designer drugs. Anal Bioanal Chem. 2015;407:6301-6315.

70. Wurita $A$, Hasegawa $K$, Minakata $K$, et al. Identification and quantitation of 5-fluoro-ADB-PINACA and MAB-CHMINACA in dubious herbal products. Forensic Toxicol. 2015;33:213-220.

71. Hasegawa K, Wurita A, Minakata K, et al. Postmortem distribution of AB-CHMINACA, 5-fluoro-AMB, and diphenidine in body fluids and solid tissues in a fatal poisoning case: usefulness of adipose tissue for detection of the drugs in unchanged forms. Forensic Toxicol. 2015;33:45-53.

72. Hasegawa K, Wurita A, Minakata K, et al. Postmortem distribution of MAB-CHMINACA in body fluids and solid tissues of a human cadaver. Forensic Toxicol. 2015;33:380-387.

73. Hasegawa K, Wurita A, Minakata K, et al. Identification and quantitation of 5 -fluoro-ADB, one of the most dangerous synthetic cannabinoids, in the stomach contents and solid tissues of a human cadaver and in some herbal products. Forensic Toxicol. 2015;33:112-121.

74. Namera A, Kawamura M, Nakamoto A, et al. Comprehensive review of the detection methods for synthetic cannabinoids and cathinones. Forensic Toxicol. 2015;33:75-194.

75. Brandt SD, King LA, Evans-Brown M. The new drug phenomenon. Drug Test Anal. 2014;6:587-597.

76. Priller J, Briley EM, Mansouri J, et al. Mead ethanolamide, a novel eicosanoid, is an agonist for the central (CB1) and peripheral (CB2) cannabinoid receptors. Mol Pharmacol. 1995;48:288-292.

77. Hanus L, Gopher A, Almog S, et al. Two new unsaturated fatty acid ethanolamides in brain that bind to the cannabinoid receptor. J Med Chem. 1993;36:3032-3034.

78. U.S. Department of Justice. Drug Enforcement Administration. Microgram Bull. 2009;42:23-24.

79. U.S. Department of Justice. Drug Enforcement Administration. Microgram Bull. 2009;42:89.

80. EMCDDA. Perspectives on drugs: synthetic cannabinoids in Europe, 2015. Available at: www.emcdda.europa.eu/topics/pods/synthetic-cannabinoids (Accessed December 1, 2015).

81. Thomas BF, Wiley JL, Endres GW. Synthetic cannabinoids are recurring chemical threats. Cayman Curr. 2015:26:1-3.

82. Copeland CR, Maheux CR, Arnold DJ, et al. Isolation, characterization and confirmation of a novel benzimidazole cannabinoid found simultaneously in two separate crime lab samples in the United States and Canada. Forensic Drug Rev, 2013. Available at: www.forensicdrugreview .com/JWH\%20018\%20Benzimidazole\%20analog.pdf (Accessed December 1, 2015)

Cite this article as: Shevyrin V, Melkozerov V, Endres GW, Shafran Y, Morzherin Y (2016) On a new cannabinoid classification system: a sight on the illegal market of novel psychoactive substances, Cannabis and Cannabinoid Research 1:1, 186-194, DOI: 10.1089/ can.2016.0004.

Abbreviations Used
NPSs $=$ novel psychoactive substances
$\mathrm{THC}=\Delta^{9}$-tetrahydrocannabinol

\section{Publish in Cannabis and Cannabinoid Research}

Cannabis and

Cannabinoid

Research
- Immediate, unrestricted online access

- Rigorous peer review

- Compliance with open access mandates

- Authors retain copyright

- Highly indexed

- Targeted email marketing

liebertpub.com/can 